\title{
Approximation of the Cubic Functional Equation in Non-Archimedean Normed Spaces : Direct and Fixed Point Method
}

\author{
Shalini Tomar ${ }^{1 *}$, Nawneet Hooda ${ }^{2}$ \\ ${ }^{1}$ Dept. of Mathematics, Kanya Mahavidyalaya, MD University, Kharkhoda ,Sonepat,India \\ ${ }^{2}$ Dept. of Mathematics, DCRUST, Murthal, Sonepat,India \\ "Corresponding Author: s_saroha30@yahoo.com
}

Available online at: www.isroset.org

Received: 03/Jun/2018, Revised: 11/Jun/2018, Accepted: 24/Jun/2018, Online: 30/Jun/2018

\begin{abstract}
In this paper, we will consider the following form of cubic functional equation: $f(k x+y)-f(x+k y)=$ $(\mathrm{k}-1)(\mathrm{k}+1)^{2}[\mathrm{f}(\mathrm{x})-\mathrm{f}(\mathrm{y})]-\mathrm{k}(\mathrm{k}-1) \mathrm{f}(\mathrm{x}-\mathrm{y})$ for a positive integer $\mathrm{k}$ greater than 2. We will investigate the Hyers-Ulam-Rassias stability of cubic functional equation using two different approaches i.e. direct and fixed point method in non-Archimedean normed spaces.
\end{abstract}

Keywords-Hyers-Ulam-Rassias stability, Cubic functional equation and non-archimedean normed spaces.

Mathematical subject classification- 39B72, 47H09.

\section{INTRODUCTION}

Ulam[1] was first who raised a question of stability of group homomorphisms, which is as following:"When is it true that a function which approximately satisfies a functional equation it must be close to an exact solution of $\varepsilon$ ?". If the problem accepts a solution, we say that the equation $\varepsilon$ is stable.

D. H. Hyers [9] answered Ulam by assuming the groups as Banach spaces. Then Th. M. Rassias[16] gave a generalized version of the theorem of Hyers for approximately linear mappings. The terminology Hyers-Ulam-Rassias stability originates from this historical background. In1994,Gavruta [6] proved a generalization of Rassias theorem by replacing the bound $\varepsilon\left(\|x\|^{\mathrm{p}}+\|\mathrm{y}\|^{\mathrm{p}}\right)$ by a general control function $\varphi(\mathrm{x}, \mathrm{y})$.

The functional equation $f(2 x+y)+f(2 x-y)=2 f(x+y)+2 f(x-y)+12 f(x)$ is said to be the cubic functional equation since $c x^{3}$ is its solution. The stability problem for the cubic functional equation was proved by Jun and Kim[10] for mappings $\mathrm{f}: \mathrm{X} \rightarrow \mathrm{Ywhere} \mathrm{X}$ is a real normed space and $\mathrm{Y}$ is Banach space. The stability problems of several functional equations have been extensively investigated by a number of authors $[2,4,5,12,14,15]$. Recently, we[8] introduced the following cubic functional equation

$$
f(k x+y)-f(x+k y)=(k-1)(k+1)^{2}[f(x)-f(y)]-k(k-1) f(x-y)
$$

and proved its generalized Hyers-Ulam-Rassias stability in Random normed spaces. Now we will prove the generalized Hyers-Ulam-Rassias stability of it in non-Archimedean Normed spaces.

\section{PRELIMINARIES}

In 1897, Hensel[7] introduced a normed space which does not have the Archimedean property.The most important examples of non-Archimedean spaces are p-adic numbers. By a Non-Archimedean field we mean a field K equipped with a function $|\diamond|: \mathrm{K} \rightarrow$ $\mathrm{R}$, such that for any $\mathrm{a}, \mathrm{b} \in \mathrm{K}$ we have

- $|\mathrm{a}| \geq 0$ and equality holds iff $\mathrm{a}=0$,

- $|a b|=|a||b|$,

- $|a+b| \leq \max \{|a|,|b|\}$. 
The third condition is known as strict triangle inequality. By second, we have $|1|=|-1|=1$.From third, with the help of induction, it follows that $|n| \leq 1$ for each integer $n$. We always assume in addition that $|\vartheta|$ is non trivial, i.e. there is an $a_{0} \in K$ such that $\left|a_{0}\right| \notin$ $\{0,1\}$.

Definition 1: Let $X$ be a vector space over a field $K$ with a non-Archimedean valuation $|\circ| . A$ function $\|\circ\|: X \rightarrow[0, \infty)$ is called a non-Archimedean norm if the following conditions hold:

- $\|\mathrm{x}\|=0$ if and if $\mathrm{x}=0$ for all $\mathrm{x} \in \mathrm{X}$,

- $\quad\|\mathrm{rx}\|=|\mathrm{r}|\|\mathrm{x}\|$ for all $\mathrm{r} \in \mathrm{K}$ and $\mathrm{x} \in \mathrm{X}$,

- (strong triangle inequality) $\|\mathrm{x}+\mathrm{y}\| \leq \max \{\|\mathrm{x}\|,\|\mathrm{y}\|\}$ for all $\mathrm{x}, \mathrm{y} \in \mathrm{X}$.

Then $(\mathrm{X},\|\circ\|)$ is called a non-Archimedean normed space.

Definition 2: Let $\left\{x_{n}\right\}$ be a sequence in a non-Archimedean normed space $X$.

1. A sequence $\left\{x_{n}\right\}_{n=1}^{\infty}$ in a non-Archimedean space is a Cauchy sequence if and only if, the sequence $\left\{x_{n+1}-x_{n}\right\}_{n=1}^{\infty}$ converges to zero.

2. The sequence $\left\{x_{n}\right\}$ is said to be convergent if, for any $\varepsilon>0$ there are a positive integer $N$ and $x \in X$ such that $\left\|x_{n}-x\right\| \leq \varepsilon$ for all $n \geq N$. Then, the point $x \in X$ is called the limit of the sequence $\left\{x_{n}\right\}$, which is denoted by $\lim _{\mathrm{n} \rightarrow \infty} \mathrm{x}_{\mathrm{n}}=\mathrm{x}$.

3. If every Cauchy sequence in X converges, then the non-Archimedean normed space X is called a non-Archimedean Banach space.

Definition 2:[11] Let $\mathrm{X}$ be a non-empty set. $\mathrm{A} \mathrm{d}: \mathrm{X} \times \mathrm{X} \rightarrow[0, \infty]$ is called a complete generalized metric on $\mathrm{X}$ if $\mathrm{d}$ satisfies the following conditions:

- $\mathrm{d}(\mathrm{x}, \mathrm{y})=0$ if and only if $\mathrm{x}=\mathrm{y}$ for all $\mathrm{x}, \mathrm{y} \in \mathrm{X}$,

- $\mathrm{d}(\mathrm{x}, \mathrm{y})=\mathrm{d}(\mathrm{x}, \mathrm{y})$ for all $\mathrm{x}, \mathrm{y} \in \mathrm{X}$,

- $\mathrm{d}(\mathrm{x}, \mathrm{z}) \leq \mathrm{d}(\mathrm{x}, \mathrm{y})+\mathrm{d}(\mathrm{y}, \mathrm{z})$ for all $\mathrm{x}, \mathrm{y}, \mathrm{z} \in \mathrm{X}$,

- Every d-Cauchy sequence in $X$ is d-convergent, i.e. $\lim _{m, n \rightarrow \infty} d\left(x_{n}, x_{m}\right)=0$ for a sequence $x_{n} \in X(n=1,2, \ldots)$ implies the existence of an element $x \in X$ with $\lim _{n \rightarrow \infty} d\left(x, x_{n}\right)=0$.

The ordered pair $(\mathrm{X}, \mathrm{d})$ is called complete generalized metric space.It differs from the usual complete metric space by the fact that not every two points in $\mathrm{X}$ have necessarily a finite distance.

Theorem 1:[3] Let $(X, d)$ be a complete generalized metric space and $\mathrm{J}: \mathrm{X} \rightarrow \mathrm{X}$ a strictly contractive mapping with Lipschitz constant $\mathrm{L}<1$. Then, for all $\mathrm{x} \in \mathrm{X}$, either $\mathbf{d}\left(\mathbf{J}^{\mathbf{n}} \mathbf{x}, \mathbf{J}^{\mathbf{n}+\mathbf{1}} \mathbf{x}\right)=\infty$ for all nonnegative integers $\mathbf{n}$ or there exists a positive integer $\mathbf{n}_{\mathbf{0}}$ such that

1. $\mathrm{d}\left(\mathrm{J}^{\mathrm{n}} \mathrm{x}, \mathrm{J}^{\mathrm{n}+1} \mathrm{x}\right)<\infty$ for all $\mathrm{n} \geq \mathrm{n}_{0}$;

2. the sequence $\left\{\mathrm{J}^{\mathrm{n}} \mathrm{x}\right\}$ converges to a fixed point $\mathrm{y}^{*}$ of $\mathrm{J}$;

3. $\mathrm{y}^{*}$ is the unique fixed point of $\mathrm{J}$ in the set $\mathrm{Y}=\left\{\mathrm{y} \in \mathrm{X}: \mathrm{d}\left(\mathrm{J}^{\mathrm{n}_{0}} \mathrm{x}, \mathrm{y}\right)<\infty\right\}$;

4. $d\left(y, y^{*}\right) \leq(1 /(1-L)) d(y, J y)$ for all $y \in Y$.

III. STABILITY OF FUNCTIONAL EQUATION (1) IN NON-ARCHIMEDEAN SPACE: A DIRECT METHOD

For this section, we suppose that $\mathrm{G}$ is an additive semigroup and $\mathrm{X}$ is a complete non-Archimedean space.

Theorem 2: Let $\Phi: \mathrm{G}^{2} \rightarrow[0,+\infty)$ be a function such that

$$
\lim _{\mathrm{n} \rightarrow \infty}|\mathrm{k}|^{3 \mathrm{n}} \Phi\left(\frac{\mathrm{x}}{\mathrm{k}^{\mathrm{n}}}, \frac{\mathrm{y}}{\mathrm{k}^{\mathrm{n}}}\right)=0
$$

for all $x, y \in G$ and let for each $x \in G$ the limit

$$
\phi(\mathrm{x})=\lim _{\mathrm{n} \rightarrow \infty} \max \left\{|\mathrm{k}|^{3 \mathrm{~m}+3} \Phi\left(\frac{\mathrm{x}}{\mathrm{k}^{\mathrm{m}+1}}, 0\right) ; 0 \leq \mathrm{m}<n\right\}
$$


exists. Suppose that $f: G \rightarrow X$ a mapping with $f(0)=0$ and satisfying the following inequality

$$
\left\|f(k x+y)-f(x+k y)-(k-1)(k+1)^{2}[f(x)-f(y)]+k(k-1) f(x-y)\right\| \leq \Phi(x, y)
$$

Then,the limit $C(x)=\lim _{n \rightarrow \infty} k^{3 n} f\left(\frac{x}{k^{n}}\right)$ exists for all $x \in G$ and defines a cubic mapping $C: G \rightarrow X$ such that

$$
\|f(x)-C(x)\| \leq \frac{\phi(x)}{|k|^{3}}
$$

Also $\mathrm{C}$ is the unique cubic mapping satisfying (5),if

$$
\lim _{\mathrm{j} \rightarrow \infty} \lim _{\mathrm{n} \rightarrow \infty} \max \left\{|\mathrm{k}|^{3 \mathrm{~m}+3} \Phi\left(\frac{\mathrm{x}}{\mathrm{k}^{\mathrm{m}+1}}, 0\right) ; \mathrm{j} \leq \mathrm{m}<n+j\right\}=0 .
$$

Proof: Existence- Putting $y=0$ in (4), we get

$$
\left\|\mathrm{f}(\mathrm{kx})-\mathrm{k}^{3} \mathrm{f}(\mathrm{x})\right\| \leq \Phi(\mathrm{x}, 0)
$$

for all $x \in G$. Replacing $x$ by $x / k^{n+1}$ in (7) and multiplying by $|k|^{3 n}$, we obtain

i.e.

$$
\left\|k^{3 n} f\left(\frac{x}{k^{n}}\right)-k^{3 n+3} f\left(\frac{x}{k^{n+1}}\right)\right\| \leq|k|^{3 n} \Phi\left(\frac{x}{k^{n+1}}, 0\right)
$$

$$
\left\|k^{3 n+3} f\left(\frac{x}{k^{n+1}}\right)-k^{3 n} f\left(\frac{x}{k^{n}}\right)\right\| \leq|k|^{3 n} \Phi\left(\frac{x}{k^{n+1}}, 0\right)
$$

It can be easily seen from (2) and (8) that the sequence $\left\{\mathrm{k}^{3 \mathrm{n}} \mathrm{f}\left(\frac{\mathrm{x}}{\mathrm{k}^{\mathrm{n}}}\right)\right\}_{\mathrm{n} \geq 1}$ is a cauchy sequence. Since $\mathrm{X}$ is complete, therefore $\left\{\mathrm{k}^{3 \mathrm{n}} \mathrm{f}\left(\frac{\mathrm{x}}{\mathrm{k}^{\mathrm{n}}}\right)\right\}_{\mathrm{n} \geq 1}$ is convergent. Set $\mathrm{C}(\mathrm{x})=\lim _{\mathrm{n} \rightarrow \infty}\left\{\mathrm{k}^{3 \mathrm{n}} \mathrm{f}\left(\frac{\mathrm{x}}{\mathrm{k}^{\mathrm{n}}}\right)\right\}$.

With the help of induction, we can easily show that

$$
\left\|\mid \mathrm{k}^{3 \mathrm{n}} \mathrm{f}\left(\frac{\mathrm{x}}{\mathrm{k}^{\mathrm{n}}}\right)-\mathrm{f}(\mathrm{x})\right\| \leq \frac{1}{\left|\mathrm{k}^{3}\right|} \max \left\{|\mathrm{k}|^{3 \mathrm{~m}+3} \Phi\left(\frac{\mathrm{x}}{\mathrm{k}^{\mathrm{m}+1}}, 0\right) ; 0 \leq \mathrm{m}<n\right\}
$$

for all $\mathrm{n} \in \mathrm{N}$ and for all $\mathrm{x} \in \mathrm{G}$.By taking limit $\mathrm{n} \rightarrow \infty$ in (9) and using (3), we get.

$$
\lim _{\mathrm{n} \rightarrow \infty}|| \mathrm{k}^{3 \mathrm{n}} \mathrm{f}\left(\frac{\mathrm{x}}{\mathrm{k}^{\mathrm{n}}}\right)-\mathrm{f}(\mathrm{x}) \| \leq \frac{1}{\left|\mathrm{k}^{3}\right|} \phi(\mathrm{x})
$$

which proves the inequality (5). By (2) and (4), we get

$$
\begin{array}{r}
\left\|C(k x+y)-C(x+k y)-(k-1)(k+1)^{2}[C(x)-C(y)]+k(k-1) C(x-y)\right\| \\
=\lim _{n \rightarrow \infty} \| k^{3 n} f\left(\frac{k x+y}{k^{n}}\right)-k^{3 n} f\left(\frac{x+k y}{k^{n}}\right)-(k-1)(k+1)^{2} k^{3 n}\left[f\left(\frac{x}{k^{n}}\right)-f\left(\frac{y}{k^{n}}\right)\right]+ \\
k^{3 n+1}(k-1) f\left(\frac{x-y}{k^{n}}\right) \| \leq \lim _{n \rightarrow \infty}|k|^{3 n} \Phi\left(\frac{x}{k^{n}}, \frac{y}{k^{n}}\right)=0
\end{array}
$$

for all $\mathrm{x}, \mathrm{y} \in \mathrm{G}$. Therefore, the function $\mathrm{C}: \mathrm{G} \rightarrow \mathrm{X}$ satisfies (1).

Uniqueness-To prove the uniqueness of $C$, let $Q: G \rightarrow X$ be another function which satisfies (5).Then,

$$
\begin{gathered}
\|C(x)-Q(x)\|=\lim _{j \rightarrow \infty}|k|^{3 j}\left\|C\left(\frac{x}{k^{j}}\right)-Q\left(\frac{x}{k^{j}}\right)\right\| \\
\leq \lim _{j \rightarrow \infty}|k|^{3 j} \max \left\{\left\|C\left(\frac{x}{k^{j}}\right)-f\left(\frac{x}{k^{j}}\right)\right\|,\left\|f\left(\frac{x}{k^{j}}\right)-Q\left(\frac{x}{k^{j}}\right)\right\|\right\} \\
\leq \lim _{j \rightarrow \infty} \lim _{n \rightarrow \infty} \max \left\{|k|^{3 m+3} \Phi\left(\frac{x}{k^{m+1}}, 0\right) ; j \leq m<n+j\right\}=0
\end{gathered}
$$

for all $\mathrm{x} \in \mathrm{G}$, therefore $\mathrm{C}=\mathrm{Q}$.Hence the proof.

Corollary 1: Let $\mathbf{\tau}:[\mathbf{0}, \infty) \rightarrow[\mathbf{0}, \infty)$ be a function satisfying

$$
\begin{gathered}
\tau\left(\frac{\mathrm{t}}{|\mathrm{k}|}\right) \leq \tau\left(\frac{1}{|\mathrm{k}|}\right) \tau(\mathrm{t}),(\mathrm{t} \geq 0) \\
\tau\left(\frac{1}{|\mathrm{k}|}\right)<|\mathrm{k}|^{-3} \text { and } \tau(0)=0 .
\end{gathered}
$$

Also let $\delta>0$ and $\mathrm{f}: \mathrm{G} \rightarrow \mathrm{X}$ a mapping with $\mathrm{f}(0)=0$ and satisfying the following inequality

$$
\left\|f(k x+y)-f(x+k y)-(k-1)(k+1)^{2}[f(x)-f(y)]+k(k-1) f(x-y)\right\| \leq \delta(\tau(|| x||)+\tau(\|y\|))
$$

for all $\mathrm{x}, \mathrm{y} \in \mathrm{G}$. Then, the limit $\mathrm{C}(\mathrm{x})=\lim _{\mathrm{n} \rightarrow \infty} \mathrm{k}^{3 \mathrm{n}} \mathrm{f}\left(\frac{\mathrm{x}}{\mathrm{k}^{\mathrm{n}}}\right)$ exists for all $\mathrm{x} \in \mathrm{G}$ and defines a cubic mapping $\mathrm{C}: \mathrm{G} \rightarrow \mathrm{X}$ such that

$$
\|\mathrm{f}(\mathrm{x})-\mathrm{C}(\mathrm{x})\| \leq \frac{\delta \tau(\|\mathrm{x}\|)}{|\mathrm{k}|^{3}} \text {. }
$$

Proof: Defining $\Phi: \mathrm{G}^{2} \rightarrow[0, \infty)$ by $\Phi(\mathrm{x}, \mathrm{y})=\delta(\tau(\|\mathrm{x}\|)+\tau(\|\mathrm{y}\|))$, we have

$$
\lim _{\mathrm{n} \rightarrow \infty}|\mathrm{k}|^{3 \mathrm{n}} \Phi\left(\frac{\mathrm{x}}{\mathrm{k}^{\mathrm{n}}}, \frac{\mathrm{y}}{\mathrm{k}^{\mathrm{n}}}\right) \leq \lim _{\mathrm{n} \rightarrow \infty}\left(|\mathrm{k}|^{3} \tau\left(\frac{1}{|\mathrm{k}|}\right)\right)^{\mathrm{n}} \Phi(\mathrm{x}, \mathrm{y})=0
$$

and $\phi(\mathrm{x})=\lim _{\mathrm{n} \rightarrow \infty} \max \left\{|\mathrm{k}|^{3 \mathrm{~m}+3} \Phi\left(\frac{\mathrm{x}}{\mathrm{k}^{\mathrm{m}+1}}, 0\right) ; 0 \leq \mathrm{m}<n\right\}=|k|^{3} \Phi\left(\frac{\mathrm{x}}{\mathrm{k}}, 0\right)=\delta \tau(\| \mathrm{x}||)$ 
for all $\mathrm{x}, \mathrm{y} \in \mathrm{G}$. Applying previous theorem we get the desired result.

Theorem 3: Let $\mathbf{\Phi}: \mathbf{G}^{2} \rightarrow[0,+\infty)$ be a function such that

$$
\lim _{\mathrm{n} \rightarrow \infty} \frac{\Phi\left(\mathrm{k}^{\mathrm{n}} \mathrm{x}, \mathrm{k}^{\mathrm{n}} \mathrm{y}\right)}{|\mathrm{k}|^{3 \mathrm{n}}}=0
$$

for all $\mathrm{x}, \mathrm{y} \in \mathrm{G}$ and let for each $\mathrm{x} \in \mathrm{G}$ the limit

$$
\phi(\mathrm{x})=\lim _{\mathrm{n} \rightarrow \infty} \max \left\{\frac{\Phi\left(\mathrm{k}_{\mathrm{m}, 0)}\right.}{|\mathrm{k}|^{3 \mathrm{~m}+3}} ; 0 \leq \mathrm{m}<n\right\}
$$

exists. Suppose that $f: G \rightarrow X$ a mapping with $f(0)=0$ and satisfying (4). Then,the limit $C(x)=\lim _{n \rightarrow \infty} \frac{f\left(k^{n} x\right)}{k^{3 n}}$ exists for all $\mathrm{x} \in \mathrm{G}$ and defines a cubic mapping $\mathrm{C}: \mathrm{G} \rightarrow \mathrm{X}$ such that

$$
\|f(x)-C(x)\| \leq \phi(x)
$$

Also $\mathrm{C}$ is the unique cubic mapping satisfying (16), if

$$
\lim _{j \rightarrow \infty} \lim _{n \rightarrow \infty} \max \left\{\frac{\Phi\left(\mathrm{k}^{\mathrm{m}, 0)}\right.}{|\mathrm{k}|^{3 \mathrm{~m}+3}} ; \mathrm{j} \leq \mathrm{m}<n+j\right\}=0 .
$$

Proof: Putting $\mathrm{y}=0$ and replacing $\mathrm{x}$ by $\mathrm{k}^{\mathrm{n}} \mathrm{x}$, then applying similar arguments as in previous theorem we can get the desired result.

Corollary 2: Let $\boldsymbol{\tau}:[\mathbf{0}, \infty) \rightarrow[0,+\infty)$ be a function satisfying

$$
\begin{aligned}
& \tau(|\mathrm{k}| \mathrm{t}) \leq \tau(|\mathrm{k}|) \tau(\mathrm{t}),(\mathrm{t} \geq 0) \\
& \tau(|\mathrm{k}|)<|\mathrm{k}|^{3} \text { and } \tau(0)=0
\end{aligned}
$$

Also let $\delta>0$ and $f: G \rightarrow X$ a mapping with $f(0)=0$ and satisfying (12) then, the limit $C(x)=\lim _{n \rightarrow \infty} \frac{f\left(k^{n} x\right)}{k^{3 n}}$ exists for all $\mathrm{x} \in \mathrm{G}$ and defines a cubic mapping $\mathrm{C}: \mathrm{G} \rightarrow \mathrm{X}$ such that

$$
\|f(x)-C(x)\| \leq \delta \tau(\|x\|) .
$$

Proof: Defining $\Phi: \mathrm{G}^{2} \rightarrow[0, \infty)$ by $\phi(\mathrm{x}, \mathrm{y})=\delta(\tau(\|\mathrm{x}\|)+\tau(\|\mathrm{y}\|))$, we have

$$
\begin{gathered}
\lim _{\mathrm{n} \rightarrow \infty} \frac{\Phi\left(\mathrm{k}^{\mathrm{n}} \mathrm{x}, \mathrm{k}^{\mathrm{n}} \mathrm{y}\right)}{|\mathrm{k}|^{3 \mathrm{n}}} \leq \lim _{\mathrm{n} \rightarrow \infty}\left(\frac{\tau(|| \mathrm{k}||)}{|\mathrm{k}|^{3}}\right)^{\mathrm{n}} \Phi(\mathrm{x}, \mathrm{y})=0 \\
\phi(\mathrm{x})=\lim _{\mathrm{n} \rightarrow \infty} \max \left\{\frac{\Phi\left(\mathrm{k}^{\mathrm{m}} \mathrm{x}, 0\right)}{|\mathrm{k}|^{3 \mathrm{~m}+3}} ; 0 \leq \mathrm{m}<n\right\}=\frac{\Phi(\mathrm{kx}, 0)}{|\mathrm{k}|^{3}}=\delta \tau(\| \mathrm{x}||)
\end{gathered}
$$

for all $\mathrm{x}, \mathrm{y} \in \mathrm{G}$. Applying previous theorem we get the desired result.

\section{STABILITY OF FUNCTIONAL EQUATION (1) IN NON-ARCHIMEDEAN SPACE: A FIXED POINT METHOD}

For this section, $\mathrm{X}$ is an non-Archimedean normed space and $\mathrm{Y}$ is a complete non-Archimedean space. Also $\left|\mathrm{m}^{3}\right| \neq 1$.

Theorem 4: Let $\boldsymbol{\Phi}: \mathbf{X}^{2} \rightarrow[\mathbf{0},+\infty)$ be a function such that there exists an $\boldsymbol{\delta}<\mathbf{1}$ with

$$
\Phi\left(\frac{\mathrm{x}}{\mathrm{k}}, \frac{\mathrm{y}}{\mathrm{k}}\right) \leq \frac{\delta \Phi(\mathrm{x}, \mathrm{y})}{|\mathrm{k}|^{3}}
$$

for all $\mathrm{x}, \mathrm{y} \in \mathrm{X}$.Suppose that $\mathrm{f}: \mathrm{X} \rightarrow \mathrm{Y}$ a mapping with $\mathrm{f}(0)=0$ and satisfying the following inequality

$$
\left\|f(k x+y)-f(x+k y)-(k-1)(k+1)^{2}[f(x)-f(y)]+k(k-1) f(x-y)\right\| \leq \Phi(x, y)
$$

for all $\mathrm{x}, \mathrm{y} \in \mathrm{X}$.Then there exists a unique cubic mapping $\mathrm{C}: \mathrm{X} \rightarrow \mathrm{Y}$ such that

for all $\mathrm{x} \in \mathrm{X}$.

$$
\|\mathrm{f}(\mathrm{x})-\mathrm{C}(\mathrm{x})\| \leq \frac{\delta \Phi(\mathrm{x}, 0)}{|\mathrm{k}|^{3}(1-\delta)}
$$

Proof: Putting $y=0$ in (20) and replacing $x$ by $\frac{x}{k}$, we have

for all $\mathrm{x} \in \mathrm{X}$. Consider the set

$$
\left\|\mathrm{k}^{3} \mathrm{f}\left(\frac{\mathrm{x}}{\mathrm{k}}\right)-\mathrm{f}(\mathrm{x})\right\| \leq \Phi\left(\frac{\mathrm{x}}{\mathrm{k}}, 0\right)
$$

and the generalised metric $\mathrm{d}$ in $\mathrm{S}$ is defined by

$$
S=\{g: X \rightarrow Y ; g(0)=0\}
$$

$$
\mathrm{d}(\mathrm{g}, \mathrm{h})=\inf _{\delta \in \mathrm{R}^{+}}\{\|\mathrm{g}(\mathrm{x})-\mathrm{h}(\mathrm{x})\| \leq \delta \Phi(\mathrm{x}, 0), \forall \mathrm{x} \in \mathrm{X}\}
$$

where inf $\emptyset=+\infty$. Then, as in the proof of [13], we can show that $(\mathrm{S}, \mathrm{d})$ is a generalised complete metric space.

Now, let us define an operator $\Delta: \mathrm{S} \rightarrow \mathrm{S}$ such that

$$
(\Delta h)(x)=k^{3} h\left(\frac{x}{k}\right)
$$


for all $x \in X$.We assert that $\Delta$ is strictly contractive on $S$.

Given $g, h \in S$, let $c \in R^{+}$be an arbitrary constant with $d(g, h)<c$, that is

for all $x \in X$, and so

$$
\|\mathrm{g}(\mathrm{x})-\mathrm{h}(\mathrm{x})\| \leq \mathrm{c} \Phi(\mathrm{x}, 0)
$$

$$
\begin{aligned}
\|(\Delta \mathrm{g})(\mathrm{x})- & (\Delta \mathrm{h})(\mathrm{x})\|=\| \mid \mathrm{k}^{3} \mathrm{~g}\left(\frac{\mathrm{x}}{\mathrm{k}}\right)-\mathrm{k}^{3} \mathrm{~h}\left(\frac{\mathrm{x}}{\mathrm{k}}\right) \| \\
& \leq|\mathrm{k}|^{3} \delta \Phi\left(\frac{\mathrm{x}}{\mathrm{k}}, 0\right) \leq|\mathrm{k}|^{3} \frac{\delta \mathrm{c}}{|\mathrm{k}|^{3}} \Phi(\mathrm{x}, 0)
\end{aligned}
$$

for all $\mathrm{x} \in \mathrm{X}$. Thus $\mathrm{d}(\mathrm{g}, \mathrm{h})=\mathrm{c}$ implies that $\mathrm{d}(\Delta \mathrm{g}, \Delta \mathrm{h}))=\mathrm{d}\left(\mathrm{k}^{3} \mathrm{~g}\left(\frac{\mathrm{x}}{\mathrm{k}}\right), \mathrm{k}^{3} \mathrm{~h}\left(\frac{\mathrm{x}}{\mathrm{k}}\right)\right) \leq \delta$ c. i.e.

$$
\mathrm{d}(\Delta \mathrm{g}, \Delta \mathrm{h}))=\delta \mathrm{d}(\mathrm{g}, \mathrm{h})
$$

for any $g, h \in S$, where $\delta$ is lipschitz constant with $0<\delta<1$. Thus $\Delta$ is strictly contractive.

It follows from (22) that

$$
d(f, \Delta f)=d\left(f, k^{3} f\left(\frac{x}{k}\right)\right) \leq \frac{\delta}{|k|^{3}}
$$

By theorem (1.4), there exists a mapping $C: X \rightarrow Y$ satisfying the following

1. C is a fixed point of $\Delta$, that is,

$$
C\left(\frac{x}{k}\right)=\frac{1}{k^{3}} C(x)
$$

for all $x \in X$. The mapping $C$ is a unique fixed point of $\Delta$ in the set

$$
\Omega=\{h \in S: d(g . h)<\infty\}
$$

Thus we can say that $C$ is a unique mapping satisfying (30) such that there exist $c \in(0, \infty)$ satisfying

for all $x \in X$.

$$
\|f(x)-C(x)\| \leq \delta \Phi(x, 0)
$$

2. $d\left(\Delta^{n} f, C\right) \rightarrow 0$ as $n \rightarrow \infty$, which implies that

$$
\lim _{n \rightarrow \infty} k^{3 n} f\left(\frac{x}{k^{n}}\right)=C(x) .
$$

for all $x \in X$.

4. $\quad d(f, C) \leq d(f, \Delta f) /(1-\delta)$ with $f \in \Omega$. And by using (29) we can say that $d(f, C) \leq \delta /|k|^{3}(1-\delta)$ and so

$$
\|f(x)-C(x)\| \leq \frac{\delta \Phi(x, 0)}{|k|^{3}(1-\delta)}
$$

for all $x \in X$. Which proves the inequality (22).

Now by using (19) and (20), we can say that

$$
\begin{gathered}
\left\|C(k x+y)-C(x+k y)-(k-1)(k+1)^{2}[C(x)-C(y)]+k(k-1) C(x-y)\right\| \\
\leq \lim _{n \rightarrow \infty}|k|^{3 n} \Phi\left(\frac{x}{k^{n}}, \frac{y}{k^{n}}\right) \leq \lim _{n \rightarrow \infty}|k|^{3 n} \frac{\delta^{n}}{|k|^{3 n}} \Phi(x, y)
\end{gathered}
$$

for all $x, y \in X$ and $n \geq 1$. So for all $x, y \in X$,we have

$$
C(k x+y)-C(x+k y)=(k-1)(k+1)^{2}[C(x)-C(y)]-k(k-1) C(x-y)
$$

Thus the mapping C: $\mathrm{X} \rightarrow \mathrm{Y}$ is cubic. Hence the proof.

Corollary 3 Let $\boldsymbol{X}$ be a linear space, $\boldsymbol{\vartheta} \geq \mathbf{0}$ and $\mathrm{p} \in(\mathbf{0}, \mathbf{1})$.Let $\boldsymbol{f}: \boldsymbol{X} \rightarrow \boldsymbol{Y}$ be a mapping with $\boldsymbol{f}(\mathbf{0})=\mathbf{0}$ and satisfying $\left\|f(k x+y)-f(x+k y)-(k-1)(k+1)^{2}[f(x)-f(y)]+k(k-1) f(x-y)\right\| \leq \theta\left(\|x\|^{r}+\|y\|^{r}\right) \quad(36)$

for all $x, y \in X$.Then, for all $x \in X, C(x)=\lim _{n \rightarrow \infty} k^{3 n} f\left(\frac{x}{k^{n}}\right)$ exists and $C: X \rightarrow Y$ is a unique cubic mapping such that for all $x \in X$,we have

$$
\|f(x)-C(x)\| \leq \frac{\delta \| x||^{r}}{\left|m^{3}\right|^{r}-\left|m^{3}\right|}
$$

Proof: The proof follows from above theorem by assuming $\Phi(x, y)=\theta\left(\left.\|x\|\right|^{r}+\|y\|^{r}\right)$ for all $x, y \in X$ and taking $\delta=\left|k^{3}\right|^{1-r}$.

Theorem 5: Let $\boldsymbol{\Phi}: \mathbf{X}^{2} \rightarrow[\mathbf{0},+\infty)$ be a function such that there exists an $\boldsymbol{\delta}<\mathbf{1}$ with

$$
\Phi(\mathrm{x}, \mathrm{y}) \leq|\mathrm{k}|^{3} \delta \Phi\left(\frac{\mathrm{x}}{\mathrm{k}}, \frac{\mathrm{y}}{\mathrm{k}}\right)
$$

for all $x, y \in X$.Suppose that $f: X \rightarrow Y$ a mapping with $f(0)=0$ and satisfying the inequality (20).Then there exists a unique cubic mapping $\mathrm{C}: \mathrm{X} \rightarrow \mathrm{Y}$ such that for all $\mathrm{x} \in \mathrm{X}$, we have,

$$
\|\mathrm{f}(\mathrm{x})-\mathrm{C}(\mathrm{x})\| \leq \frac{\Phi(\mathrm{x}, 0)}{|\mathrm{k}|^{3}(1-\delta)}
$$


Proof: The proof can be easily generated from the theorem 4.

Corollary 4: Let $\mathbf{X}$ be a linear space, $\square \geq \mathbf{0}$ and $\mathrm{p} \in(\mathbf{1}, \infty)$. Let $\mathbf{f}: \mathbf{X} \rightarrow \mathbf{Y}$ be a mapping with $\mathbf{f}(\mathbf{0})=\mathbf{0}$ and satisfying (36).Then, for all $\mathbf{x} \in \mathbf{X}, \mathbf{C}(\mathbf{x})=\lim _{\mathbf{n} \rightarrow \infty} \frac{\mathbf{f}\left(\mathbf{k}^{\mathbf{n}} \mathbf{x}\right)}{\mathbf{k}^{3 \mathbf{n}}}$ exists and $\mathbf{C}: \mathbf{X} \rightarrow \mathbf{Y}$ is a unique cubic mapping such that

for all $\mathrm{x} \in \mathrm{X}$.

$$
\|f(x)-C(x)\| \leq \frac{\delta|| x||^{r}}{\left|m^{3}\right|-\left|m^{3}\right|^{r}}
$$

Proof: The proof follows from above theorem by assuming $\Phi(\mathrm{x}, \mathrm{y})=\theta\left(\left.\|\mathrm{x}\|\right|^{\mathrm{r}}+\|\mathrm{y}\|^{\mathrm{r}}\right)$ for all $\mathrm{x}, \mathrm{y} \in \mathrm{X}$ and taking $\delta=\left|\mathrm{k}^{3}\right|^{\mathrm{r}-1}$.

Remark 1:In corollaries 3 and 4 if we assume $\square(\mathbf{x}, \mathbf{y})=\left(\left\|\left.\mathbf{x}\right|^{\mathbf{p}}|| \mathbf{y}\right\|^{\mathbf{p}}\right) \mathbf{z}_{\mathbf{0}}$, then we get Ulam-Gavruta-Rassias[26] product stability. Since we put $\mathrm{y}=0$ in the functional equation,therefore this stability is obvious.

\section{REFRENCES}

[1]. S. M. Ulam,"Problems in Modern Mathematics", Science Editions, JohnWiley and Sons, New York, NY, USA,1964.

[2]. H. Azadi Kenary,"Non-Archimedean stability of Cauchy-Jensen type functional equation ", Int. J. nonlinear analysis appl., vol. 1, issue. 2, pp. $1-10,2010$

[3]. J.B. Diaz ,B. Margolis,"A fixed point theorem of the alternative for contraction on a generalized complete metric space",Bull. Amer. Math. Soc.,vol. 74,pp. 305-309, 1968.

[4]. M. Eshaghi Gordji and H. Khodaei,"Stability of Functional Equations", Lap Lambert Academic Publishing, 2010.

[5]. M. Eshaghi Gordji, S. Zolfaghari, J. M. Rassias, and M. B. Savadkouhi,"Solution and stability of a mixed type cubic and quartic functional equation in quasi-Banach spaces",Abstract and Applied Analysis, vol. 2009, Article ID 417473, 14 pages.

[6]. P. Gavruta, "A generalization of the Hyers-Ulam-Rassias stability of approximately additive mappings",J. Math. Anal. Appl., vol. 184, issue. 3, pp. 431-436, 1994.

[7]. K. Hensel, "Ubereine news Begrundung der Theorie der algebraischen Zahlen", Jahresber. Deutsch. Math., vol. 6 , pp. 83 - 88, 1897.

[8]. N. Hooda and S. Tomar,"Approximation of the cubic functional equation in random normed spaces:direct and fixed point method",Aryabhatta Journal of Mathematics and Informatics,vol. 10,issue. 1,pp. 99-114, 2018.

[9]. D. H. Hyers,"On the stability of the linear functional equation", Proc. Natl. Acad. Sci. USA, vol. 27, issue. 4, pp. $222-224$, 1941.

[10]. K.W.Jun and H.M.Kim,"The generalized Hyers-Ulam-Rassias stability problem of cubic functional equation",J. Math. Anal. Appl.,vol. 27 ,pp. 867-878, 2002.

[11]. W.A.J. Luxemburg,"On the convergence of successive approximation in the theory of ordinary differential equation",Proc. K. Ned. Aked. Wet.,Ser. A.,Indag. Math.,vol. 20,pp. 540-546, 1958.

[12]. D. Mihet, "The stability of the additive Cauchy functional equation in non-Archimedean fuzzy normed spaces", Fuzzy Sets and Systems ,vol. 161, pp. 2206-2212, 2010.

[13]. D. Mihet $\hat{A}_{\text {s }}$ and V. Radu,"On the stability of the additive Cauchy functional equation in random normed spaces",J. Math Anal Appl, vol. 343, issue. 1, pp. 567 - 572, 2008.

[14]. A. Najati, " The generalized Hyers-Ulam-Rassias stability of a cubic functional equation", Turk. J. Math., vol. 31, issue. 4, pp. 395-408, 2007.

[15]. J. M. Rassias,"On approximation of approximately linear mappings by linear mappings", J. Funct. Anal., vol. 46, issue. 1, pp. 126-130, 1982.

[16]. Th. M. Rassias,"On the stability of the linear mapping in Banach spaces", Proc. Amer. Math. Soc.,vol. 72 ,pp. 297 - $300,1978$.

[17]. M. A. Sibaha,B. Bouikhalene, and E. Elqorachi, "Ulam-Gavruta-Rassias stability of a linear functional equation", Int. J. Appl. Math. Stat., vol. 7, issue. Fe07, pp. 157-166, 2007.

\section{AUTHORS PROFILE:}

Dr. Nawneet Hooda is in the Department of Mathematics of DCRUST Murthal,Sonepat.His Area of interest is Functional Analysis.He has published Various research papers in reputed journals.

Mrs. Shalini Tomar is Assistant Professor of Mathematics in Kanya Mahavidyalaya,Kharkhoda,Sonepat.She is also persuing her Ph.D. in mathematics at the dept. of mathematics,DCRUST,Murthal,Sonepat. 